\title{
Acute medicine units: the current state of affairs in the North-West of England
}

\author{
${ }^{1} \mathrm{C}$ Jayawarna, ${ }^{2} \mathrm{D}$ Atkinson, ${ }^{3} \mathrm{SV}$ Ahmed, ${ }^{4} \mathrm{~K}$ Leong

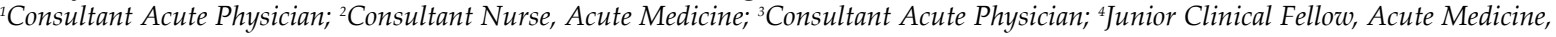 \\ Stepping Hill Hospital, Stockport, UK
}

\begin{abstract}
Studies suggest that acute medicine units (AMU) reduce inpatient mortality, length of stay and re-admissions and improve four-hour performance targets. Over the past decade or so, after evaluating the system in place, the Royal College of Physicians of London (RCPL) has made key recommendations for an efficient and effective AMU. This audit reviews the current infrastructure of regional AMUs against those RCPL recommendations in respect of facilities, service provision and staffing. A total of 22 regional hospitals in the North-West of England were invited to participate in this audit; 19 responded. Two units did not have designated AMU facilities. Not a single hospital met all basic infrastructure recommendations. Only four had the recommended bed capacity, nine had recommended cardiacmonitoring facilities and incorporated 'short-stay units', I3 used early warning systems for patient triage and six had the recommended number of consultants assigned to AMUs with a designated medical team. Notably, there were suboptimal numbers of allied healthcare professionals in most units. In summary, the majority of the AMUs in the North-West of England lack sufficient resources to meet even the most basic RCPL recommendations. A national in-depth audit is needed to determine fully the current state and thus guide future health planning.
\end{abstract}

Correspondence to SV Ahmed, Stepping Hill Hospital, Poplar Grove, Stockport SK7 2AF, UK

tel. $+44(0)$ I 614194036

e-mail

syed.ahmed@stockport.nhs.uk

KEYWORDS Acute medicine task force, acute medicine units (AMU), facilities, service provision

DECLARATION OF INTERESTS No conflict of interests declared.

\section{INTRODUCTION}

Caring for acutely ill patients admitted as medical emergencies forms a major part of medical activity in general hospitals. Many of these patients need prompt diagnosis and aggressive treatment to minimise complications or deterioration in their condition. Until recently the majority of acute medical admissions were managed by physicians combining acute care with other types of more specialist care. ${ }^{1,2}$

During a review of this traditional medical admissions process, the Royal College of Physicians of London (RCPL) realised that in some circumstances this pattern may not be ideal. A shortage of senior staff involved in managing patients in acute care could result in delays in the diagnosis, assessment and management of acutely ill patients. It was speculated that consultant physicians tasked to manage acute intake alone may improve quality of care.' A new sub-specialty of acute medicine was proposed against this background.

The Scottish Colleges highlighted this concept in their report Acute medical admissions and the future of general medicine. ${ }^{3}$ Subsequently, a working party was set up by the Federation of Medical Royal Colleges, which later released a report to focus on acute medicine as a new specialty. ${ }^{4}$ It suggested the facilities and organisation necessary to support clinical services and proposed standards of care. One of the recommen-dations was that all hospitals admitting acutely ill medical patients in sufficient numbers should have a dedicated area where these patients could be managed. The names given to this area were numerous, but the working party's report recommended calling it the acute medicine unit (AMU). ${ }^{4}$

Since that time, larger UK National Health Service (NHS) hospitals have implemented AMUs with the presumed goal of improving patient outcomes. In 2003, the Specialist Training Authority recognised acute medicine as a sub-specialty, and in August 2009 acute medicine achieved full specialty status.

Acute medicine units are now well established in the UK. They were presumed to improve the four-hour access waiting target for emergency care, improve patient flow out of the emergency department $\mathrm{t}^{5,6}$ and possibly reduce the average length of stay in hospital. ${ }^{5,7,8}$ In a systematic review by Scott and colleagues ${ }^{8}$ to assess the effectiveness of AMUs, few studies were available. One prospective study, compared against a historical control, only reported a reduction in inpatient mortality of between $0.6 \%$ and $5.6 \%$. In three studies the proportion of patients discharged without admission from the AMU increased, ranging from $8 \%$ to $25 \%$, following the establishment of an AMU. ${ }^{8}$ The proportion re-admitted to the same unit or elsewhere is unclear. Two studies highlighted improved patient and staff satisfaction with 
TABLE I Percentages of achievements within North-West England's AMUs in different categories of recommendations

\begin{tabular}{|c|c|c|}
\hline Audit standards & $\begin{array}{l}\text { Source of standards } \\
\text { (page number) }\end{array}$ & $\begin{array}{l}\% \text { of AMUs } \\
\text { meeting } \\
\text { standards }\end{array}$ \\
\hline \multicolumn{3}{|l|}{ Facilities } \\
\hline $\begin{array}{l}\text { I. The acute medicine unit (AMU) has a bed capacity which is equal to the average } \\
\text { daily patient intake to AMU plus } 10 \% \text {. }\end{array}$ & RCPL $2007^{12}(30)$ & $21 \%(4 / 19)$ \\
\hline 2. The AMU has incorporated sufficient capacity for single-sex bay accommodation. & RCPL $2007^{12}(32)$ & $21 \%(4 / 19)$ \\
\hline 3. Larger hospitals ( $>500$ beds) have level 2 care facilities embedded in the unit. & RCPL $2007^{12}(31)$ & $20 \%(1 / 5)$ \\
\hline 4. A minimum of $20 \%$ of the bed complement has fixed cardiac monitoring. & SAM"I & $47 \%(9 / 19)$ \\
\hline 5. The AMU has incorporated 'short-stay units' to ensure continuity of care. & RCPL $2007^{12}(33)$ & $47 \%(9 / 19)$ \\
\hline $\begin{array}{l}\text { 6. The AMU has adequate side-room accommodation for infection control and for } \\
\text { patients requiring privacy due to the type of their illness. }\end{array}$ & RCPL $2007^{12}(32)$ & $95 \%(18 / 19)$ \\
\hline \multicolumn{3}{|l|}{ Service provision } \\
\hline I. Ambulatory care facility is co-located within the emergency floor of acute hospitals. & RCPL $2007^{12}(10)$ & $53 \%(10 / 19)$ \\
\hline 2. Average length of stay in AMU is approximately $24-30$ hours. & RCPL $2007^{12}(33)$ & $67 \%(12 / 18)$ \\
\hline 3. An NHS Early Warning (NEW) score is in use for grading the clinical severity. & $\begin{array}{l}\text { RCPL 2007'12 (24), } \\
\text { NICE CG5010 }\end{array}$ & $89 \%(17 / 19)$ \\
\hline 4. Patients awaiting initial assessment are triaged according to NEW score. & NICE CG5010 & $68 \%(13 / 19)$ \\
\hline 5. After review on a post-take ward round, patients are triaged to a specialty. & RCPL 2007'12 (24) & $74 \%(14 / 19)$ \\
\hline \multicolumn{3}{|l|}{ Staffing } \\
\hline I. Larger hospitals (serving $>400,000$ ) have $7-12$ dedicated consultants in acute medicine. & RCPL $2004^{4}(7)$ & $0 \%(0 / 5)$ \\
\hline 2. Other hospitals have at least three dedicated acute medical consultants on AMU. & RCPL $2004^{4}(13)$ & $43 \%(6 / 14)$ \\
\hline $\begin{array}{l}\text { 3. The AMU has a full designated medical team (consultants, specialty registrars, senior } \\
\text { house officers/house officers). }\end{array}$ & $\begin{array}{l}\text { RCPL } 2007^{12}(37) \\
\text { SAM" }\end{array}$ & $37 \%(7 / 19)$ \\
\hline 4. Junior medical staff are allocated to the AMU in blocks of $2-4$ months. & RCPL $2007^{12}(37)$ & $68 \%(13 / 19)$ \\
\hline \multicolumn{3}{|l|}{ Support staff } \\
\hline 5. The AMU has a designated social service support team. & RCPL $2007^{12}(38)$ & $26 \%(5 / 19)$ \\
\hline 6. The AMU has designated occupational therapists. & RCPL $2007^{12}(38)$, SAM $^{\prime \prime}$ & $32 \%(6 / 19)$ \\
\hline 7. The AMU has designated physiotherapists. & RCPL 2007'2 (38), SAM"1" & $37 \%(7 / 19)$ \\
\hline 8. The AMU has designated pharmacists. & RCPL $2007^{12}$ (38), SAM" & $84 \%(16 / 19)$ \\
\hline
\end{tabular}

care. ${ }^{8} \mathrm{~A}$ retrospective analysis in one centre of 3,163 medical patients admitted before and after a ward was reconfigured to function as an AMU suggested no significant difference in re-admission rates. ${ }^{9}$

No studies have so far been conducted to address whether the facilities outlined as desirable in the RCPL reports have been implemented nationally. We report an audit, from selected hospitals in the North-West of England, to identify whether those recommendations have been actioned in the AMUs in the region.

\section{METHODS}

This was a retrospective audit of 22 hospitals across the North-West of England to define the infrastructure of AMUs and to compare these with the RCPL recommendations. This was carried out over a sixmonth period in 2008-09 using a modified RCPL questionnaire template (with permission).
Out of the numerous recommendations made in the RCPL Working Party's Acute Medicine Task Force report ${ }^{4}$ and the National Institute for Health and Clinical Excellence (NICE) clinical guidelines, ${ }^{10}$ only the most basic recommendations were included in the questionnaire. These covered the unit facilities, such as short-stay beds; bedside monitoring facilities, such as electrocardiogram (ECG) telemetry; and service provision, including bed capacity and daily take. Some additional questions were included to outline the average length of stay, ambulatory care provision and the use of early warning scores (aimed at identifying waiting patients who may need urgent diagnostic evaluation ${ }^{9}$ ). The availability of medical staff (both consultants and junior doctors) and allied healthcare professionals attached to the unit was also audited.

A ward manager or acute physician in all known AMUs in England's North-West was contacted to make a telephone appointment to fill out the questionnaire. Where it was not possible to get all the information by telephone, the responses were returned via email. 


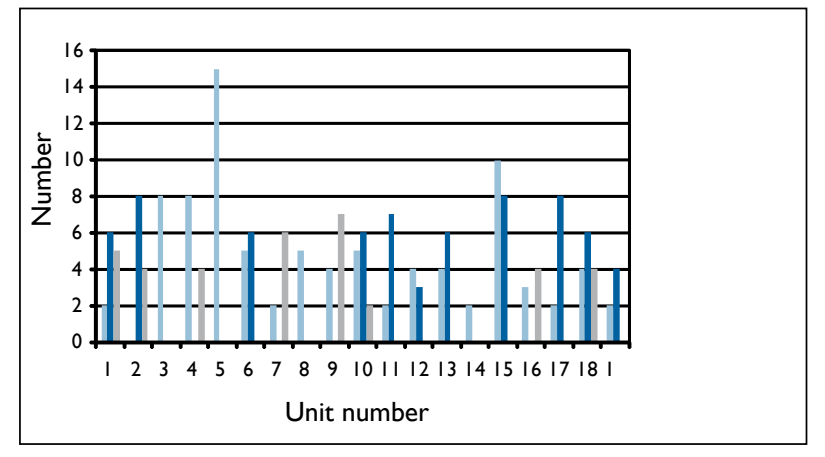

FIGURE I The most important facilities in the AMU, as recommended in the Task Force Report.

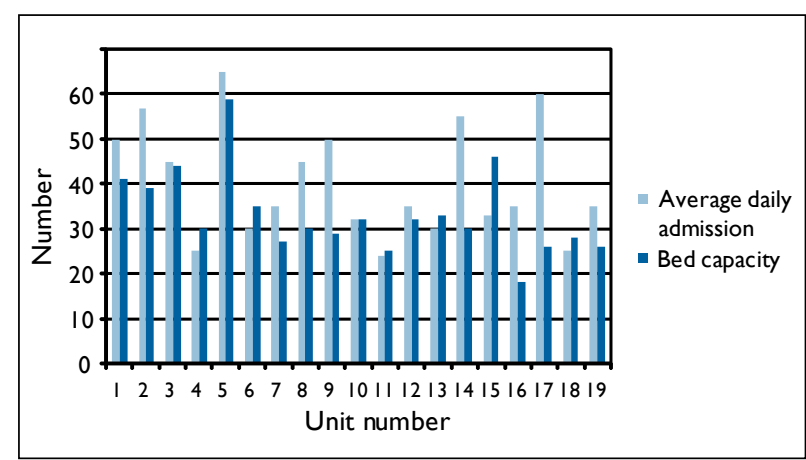

FIGURE 2 Bed capacity in relation to the average daily admission in each unit.

\section{RESULTS}

Nineteen units completed the questionnaire. One unit did not respond. Two hospitals accepting acute medical admissions in this region did not have an AMU. Five of the 19 hospitals had a bed capacity of more than 500 beds and a catchment of more than 400,000 people. The summary of audit standards and the results are listed in Table $\mathrm{I}$.

\section{Facilities (Figures I-2)}

Capacity: The Task Force suggested the minimum number of beds in an AMU would be the average number of patients admitted per 24 hours, plus $10 \%$. In this region, four out of 19 AMUs (21\%) fulfilled this requirement. Information on the daily admission rate was provided by respondents based on the statistics available to them at the time. The validity of these figures was not checked.

Gender separation: Nine out of 19 AMUs (47\%) claimed a target of single gender accommodation (non-mixed ward) as their policy. Four units had implemented this at the time of the audit.

Monitoring and observation: It was recommended that each AMU have at least $20 \%$ of its bed capacity with ECG monitoring facilities." Nine of the 19 units (47\%) had the recommended capacity, provided monitored beds and telemetry were combined. Nine units (47\%) had a 'short-stay' facility within the AMU service provision. Eighteen units met the requirement of having single

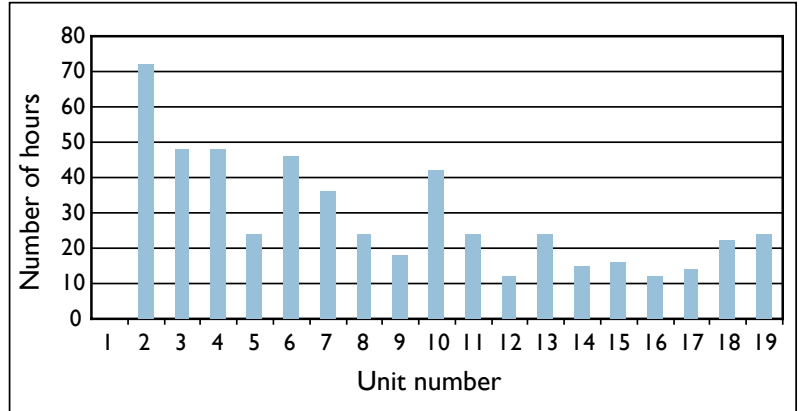

FIGURE 3 Average length of stay in each unit in hours. No data were available from unit I.

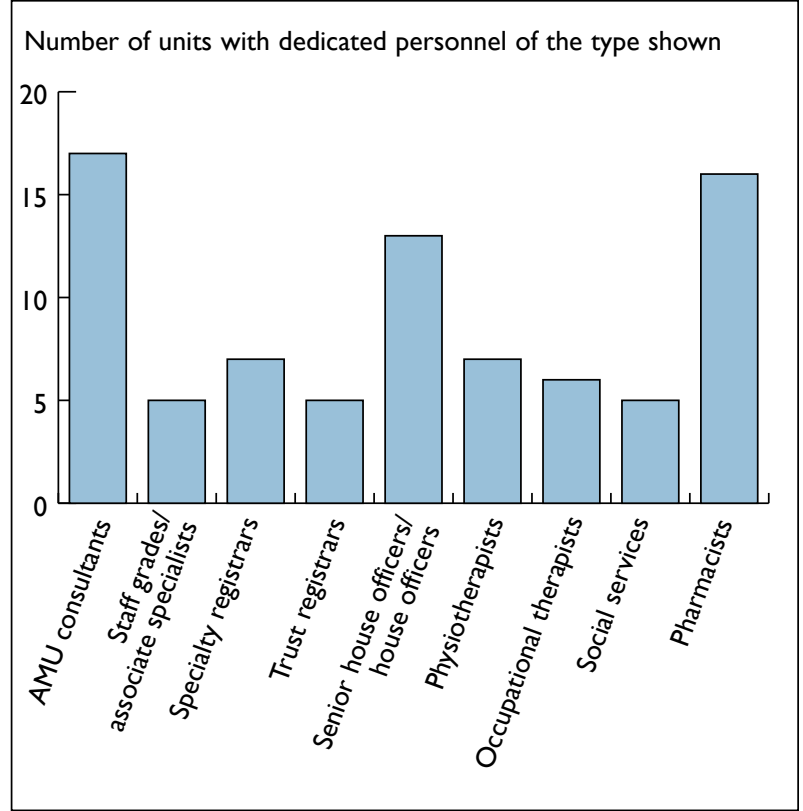

FIGURE 4 Availability of medical and non-medical staff.

rooms/isolation facilities, although neither the extent nor the need for this provision were addressed.

\section{Related service provision}

Nine units (47\%) did not have an ambulatory care (outpatient follow-up) facility supporting discharge from the AMU. Almost $90 \%$ of the AMUs claimed a policy of implementing a scoring system similar to the NHS Early Warning (NEW) score for the escalation of clinical review in sick patients. However, $32 \%$ did not take this into consideration when patients were triaged for assessment by medical staff.

The average length of stay in the AMUs ranged from 12 to 72 hours (Figure 3 ). Twelve units (63\%) had an average stay of approximately 24-30 hours, as recommended by the RCPL to allow as many patients as possible to complete their episode of care with the same clinical team. ${ }^{12}$

\section{Staffing (Figure 4)}

This audit identified several areas where staffing recommendations were not being met. The RCPL recommended having seven to 12 consultants in larger 
AMUs (those serving $>400,000$ population) and at least three full-time acute physicians in other AMUs. None of the larger hospitals had the minimum recommended number of consultants and only six other hospitals had three or more consultants committed solely to acute care.

Twelve AMUs (63\%) lacked a designated medical team attached to the AMU. Six (32\%) did not have junior trainees allocated to the unit for the recommended minimum of two to four months; this was neither conducive to satisfactory training nor providing continuity of care.

Other support staffing issues were noted in a number of AMUs: 14 (74\%) lacked assigned social service support, 13 (68\%) lacked assigned occupational therapy and 12 (63\%) lacked assigned physiotherapy. However, only three $(6 \%)$ had no pharmacist assigned to their unit.

\section{DISCUSSION}

This audit covered only the North-West of England and may not reflect the UK as a whole. In this region, the majority of AMUs are without the specified resources suggested to allow optimal function. Current UK recommendations specify staffing and facilities, including adequate bed capacity, single-sex accommodation, isolation facilities and monitored beds. These appear to remain partly unmet goals for a significant proportion of AMUs. In particular, the provision of linked short-stay and ambulatory care facilities for AMUs appears to be lacking. However, this audit does not in any way address appropriate referral to specialist care.

The NEW score is well recognised across the region and $90 \%$ of units use it in some form. While this may be encouraging, the score was paradoxically not being used

\section{REFERENCES}

I Dowdle JR. Acute medicine: past, present and future. Emerg Med J 2004; 2I:652-3. doi: I0.1 I36/emj.2003.0122II

2 Rhodes JM, Harrison B, Black D et al. General internal medicine and specialty medicine - time to rethink the relationship. J $R$ Coll Physicians Lond 1999; 33:34I-7.

3 Scottish Intercollegiate Working Party. Acute medical admissions and the future of general medicine. Edinburgh and Glasgow: Scottish Intercollegiate Working Party; 1998.

4 Royal College of Physicians of London. Acute medicine: making it work for patients. A blueprint of organisation and training. London: Royal College of Physicians of London; 2004.

5 St Noble V], Davies G, Bell D. Improving continuity of care in an acute medical unit: initial outcomes. QJM 2008; 101:529-33. doi:I0.1093/qjmed/hcn042

6 Moloney ED, Bennett K, O'Riordan D et al. Emergency department census of patients awaiting admission following reorganisation of an admission process. Emerg Med J 2006; 23:363-7. doi:10.1136/ emj.2005.028944

7 Moloney ED, Bennett K, Silke B. Effect of an acute medical admission unit on key quality indicators assessed by funnel plots. Postgrad Med J 2007; 83:659-63. doi:I0.I I36/pgmj.2007.0585II to prioritise patients for initial assessment, as per national recommendations, ${ }^{12,13}$ in approximately one-third of units. The reasons for this are not explored here.

The majority of AMUs appear to function without the suggested numbers of acute medical consultant-led teams. Achieving the required number of consultants in acute medicine per se over a very short timescale has obviously been a challenge. It is accepted that consultant supervision in an AMU is likely to improve patient care. This presumption is not supported by firm data comparing the skills of different groups of consultant staff in acute care. ${ }^{5}$ In one small study, overall length of stay was significantly lower, by an average of I.3 days, when a designated consultant was involved on admission. ${ }^{14}$ The same study suggested a $9 \%$ rise in same-day discharge without affecting short-term re-admission or mortality. The RCPL working party has suggested that junior doctors' attachments to AMUs should last at least two to four months. ${ }^{2}$ However, in this audit, only twothirds of units had this training period.

To provide the best supportive care while reducing the length of hospital stays, all AMUs should have access to physiotherapy, occupational therapy and social worker input, ${ }^{13}$ ideally as an integral part of a multidisciplinary team. A large percentage of the units surveyed do not have such teams. This gap might be bridged by redesigning the workload of existing therapists and social workers to accommodate some time in the AMU. In distinct contrast, most units appear to have a dedicated pharmacist. The reasons for this distinction are unclear.
8 Scott I, Vaughan L, Bell D. Effectiveness of acute medical units in hospitals: a systematic review. Int J Qual Health Care 2009; 21 : 397-407. doi:10.1093/intqhc/mzp045

9 Subbe CP, Kruger M, Rutherford $P$ et al.Validation of a modified Early Warning Score in medical admissions. QJM 200I; 94:52I-6. doi:I0.1093/qjmed/94.10.521

I0 National Institute for Health and Clinical Excellence. Acutely ill patients in hospital. London: NICE; 2007. Available from: http:// www.nice.org.uk/CG50

II Society for Acute Medicine. Recommendations for medical assessment (admission) units. Edinburgh: Society for Acute Medicine; 2003.

12 Royal College of Physicians of London. Acute medical care: the right person, in the right setting - first time. London: Royal College of Physicians of London; 2007.

I3 Langlands A, Dowdle R, Elliott A et al. RCPE consensus statement on acute medicine. Edinburgh: Royal College of Physicians of Edinburgh; 2008. Available from: http://www.rcpe.ac.uk/clinical-standards/ standards/final-statement-rcpe-consensus-conference-on-acutemedicine-nov-2008.pdf

I4 McNeill G, Brahmbhatt DH, Prevost AT et al. What is the effect of a consultant presence in an acute medical unit? Clin Med 2009; $9: 214-8$. 